\title{
Impacts of COVID-19 on the Ethiopian Education System
}

\author{
Tilahun Adamu Mengistie \\ University of Gondar, Gondar, Ethiopia
}

\begin{abstract}
The outbreak of COVID-19 at the end of 2019 lifted 2020 of the world in turmoil. Now, the world is absolutely in a unique environment. In all corners, today, the scientific world accompanies huge consequences from the novel coronavirus. The economic, social, educational, and political aspects of the world get into the abnormal conditions. This paper aimed to provide the current stance of Ethiopia's poorly equipped educational system, by focusing on the impacts of the novel Coronavirus in the provision of education and the government measures to alleviate problems, obstacles, challenges, and opportunities to adapt current reality.
\end{abstract}

Sci Insigt Edu Front 2020; 6(1):569-578.

Doi: 10.15354/sief.20.or011

How to Cite: Mengistie, T.A. (2020) Impacts of COVID-19 on the Ethiopian education system. Sci Insigt Edu Front, 6(1):569-578.

Keywords: Ethiopia; COVID-19; School Closure; Pandemic; Education

Correspondence to: Tilahun Adamu Mengistie, Lecturer, Department of Adult Education and Community Development, College of Education, University of Gondar, Gondar P.O. Box 196, Ethiopia.Email: tilahunadamu2009@gmail.com. 


\section{Introduction}

7 ODAY, the novel Coronavirus has hit a scientifically based world. The outbreak of Coronavirus in Wuhan of China in December 2019 brought a catastrophe in multiple dimensions of a human aspect. Since the outbreak, the virus has been addressing globally. Unusually, this novel virus highly hits the developed countries including the USA and Europe. The outbreak of the pandemic damages the developing countries' economic, social, human, and political conditions, mostly, because of their poor health system than the developed countries (Sá \& Serpa, 2020). The widespread of this virus throughout the world and particularly, in developed countries make everything upside-down.

Currently, COVID-19 contracted more than 1.5 million people and killed more than one hundred thousand people in the world. Relatively, based on the up-to-date statistics, Europe and the USA take the largest number of deaths by COVID-19, although death has registered in more than half the world's countries. This situation disturbs the lives of billions of the population. Therefore, this leads to over seven billion people to feel panic. COVID-19 has been infecting not only ordinary peoples but also the prominent leaders in the developed countries. For example, the UK's Prime Minister, Boris Johnson has become the first leader tested positive and eventually taken into St. Thomas' Hospital, London for treatment in the intensive care unit and now taken out from that room. This situation lessoned diplomats and leaders of the world to stop the diplomatic deal in face-to-face communication. Most of the leaders now continued to lead a country by using video conferences and other electronic media.

Now, both developing and developed countries have common rivalry, COVID19, exponentially spreading out the virus. To win this battle collectively, politicians, government officials, international organizations, non-governmental organizations, civil and professional association, etc., globally preparing to restrain and minimize the devastating the virus has or may have brought. Compared to the USA and European countries, in Africa, the numbers of infected people are low. However, the World Health Organization (WHO) and other institutions are claiming, as Africa will be one of the continents that will be highly attacked by COVID-19. In the second week of March 2020, WHO declared COVID-19 as a pandemic disease. This institution highlighted international communities to take urgent measures to curb the spreading pandemic.

African countries with poor infrastructure and inadequate health systems, have been adopting this international prevalence and the situation is becoming uncertain. Using their best possible alternatives, they have been taking measures to reduce the spread of the virus, though natural, social, economic, and educational aspects have been continuing to be affected. The focus of this article as a piece of opinion is on the educational sphere of Ethiopia. Specifically, it addresses how changes look like in the educational provision, alternatives that have been taking place to mitigate the challenges, and the possible opportunities that could change the current educational scenario experiencing in Ethiopia. 


\section{Methods}

In this article, the collection and analysis of publications and other documents directly related to COVID-19 and educational scenarios of this crisis period in a national, continental, and international level used as a methodology. Different legal and working documents in Ethiopia have been analyzed. In addition to reviewing the documents, the author also consulted officially recognized websites where COVID-19 related topics were released.

\section{The World's Current Scenario about COVID-19}

The world has been exposed by the global pandemic. Across a period with different places, various types of the pandemic had brought crises on the social, economic, political, educational, and other dimensions of the world. Therefore, the outbreak of COVID19 as a pandemic is not a new phenomenon. For example, Kidman and Chang (2020) insisted as the international information exchange medium like newspapers remind us about other past deadly virus outbreaks including Chain's Severe Acute Respiratory Syndrome (SARS) and the Middle East respiratory syndrome (MERS) virus. They have argued, unlike past pandemics, the COVID-19 outbreak happened at a time of the Chinese New Year celebration, which marked the millions of people to return home to celebrate with family and this contributed to the spread of the virus globally. Further, Sá and Serpa (2020) also noted that the last international pandemic that the world remembered was the Spanish flu, caused by the influenza virus H1N1 from January 1918 to December 1920. Therefore, publications showed that the current pandemic is not a strange event rather than bad and good memories in the previous viruses.

Through media, politicians and prominent individuals in arts and athletics, keep their message to reach out for the world about the importance of staying at home, about social/physical distancing and procedures to use sanitations frequently. Although these are going hard, the COVID-19 caused by the SARS-CoV-2 virus continues to kill people, deteriorate the global economy at an alarming rate, interrupts the globalization, sustains, and even widens the existing inequalities and brings the closure of social service like schooling.

Starting from its origin, the virus has spread out to Europe, the USA, Middle East, and Africa in a short period. Compared with other continents, now, the pandemic is in its highest stage in Europe and the USA. In Western countries, USA, Spain and Italy respectively leading the first three in the number of confirmed cases and Italy, Spain, USA and France respectively also leads the first four in the number of people died from COVID-19 (figures are taken from the World Health Organization website as of 10 April 2020).

In Africa, the pandemic is not as such in its highest stage but it spreads exponentially day after day. South Africa, Algeria, Cameroon, and Burkina-Faso respectively take the top first four in the number of confirmed cases in this continent. In the number of deaths from COVID-19, Algeria, Burkina-Faso and South Africa took the first 
top three ranks in Africa (figures are taken from the World Health Organization website as of 10 April 2020). The number of deaths claimed as the lowest but exponentially growing daily. However, governments, continental institutions, associations, and media, etc., in Africa fear the wave of the pandemic and they have the worst expectation that is to come. On 9 April 2020, the African Union (AU) briefed about COVID-19 in the press by noting the number of cases worldwide has more than one million. It provided a critical update on efforts by member states and finally urged for countermeasures to be taken to minimize potential fatality (messages are taken from the African Union website as of 10 April 2020).

\section{Current Situation of COVID-19 in Ethiopia}

Directly or indirectly, no country could escape from the spread of COVID-19 pandemic. Therefore, Ethiopia is on the brink to the virus. Now, Ethiopia has 69 confirmed cases and three deaths (figures are taken from the Ethiopian Ministry of Health website as of 11 April 2020). On 13 March 2020, the first case found from a foreigner, Japanese citizen who came from Burkina Faso to Ethiopia by 4 March 2020 (information are taken from the Ethiopian Ministry of Health website as of 13 March 2020). Since then, the numbers of positive cases are increasing in this poorly established health system of Ethiopia. More than 3,500 cases in Ethiopia have been tested positive for Coronavirus and it is one of the lowest tests in the world when compared with the total population expected to be more than 110 million.

To curve the potential problems of the virus may have and certainly have, the Ethiopian government has been taking its best possible measures. Starting from 16 March 2020, the Prime Minister of Ethiopia has officially announced the closure of schools, including Kindergarten to Higher Education, the prohibition of mass exercise and large meetings and called the people to shelter at home for 14 days. However, it was insufficient to contain the spread of the virus, as many of the people with hand to mouth lives could not lockdown themselves for 14 days. In addition to the above measures with reservations for key workers of the government and non-government organization, all offices are closed, transport services are interrupted, university students are returned to the home and the call for lockdown is still extended.

As I have observed, though the government urges to stay at home for an extended period, many people spending their time out of home even in provinces where virus cases were found and probably the epicenter of the pandemic like Addis Ababa. However, in cities and towns like Bahir Dar, Adama, and Injibara, where positive cases have confirmed with the spread of the virus, and government forces have been enforcing lockdown of every individual except the allowed volunteers for an unspecified period. Continuously, the government, media, and prominent individuals including legendary athlete called the whole people to stop physical contact, to use alcohol and sanitizer that could kill the virus before and after touching something, to frequently wash hands for at least 21 seconds and to stay at home unless they have urgent business. Now, the country is under a state of emergency. Since 10 April 2020, the state of emergency has 
been declared and extended for the upcoming five months to control the outbreak of the coronavirus and to minimize the potential risk. To control the spread of the virus in the headquarter AU, City of Addis Ababa, its Deputy Mayor explained that, as the door-todoor testing will begin soon with the help of volunteers and health professionals. He has insisted as the testing will hold in all Woredas, the second-lowest administrative unit of Addis Ababa, starting from those areas expected as a vulnerable for the novel Coronavirus. Many of these actions believed to decrease the impacts of COVID-19 on the overall aspects of the country. The pandemic had had concert impacts on diverse sectors of a country. Exclusively, this paper focuses on the educational aspects and scenarios happening in the education sector right after the outbreak of the Coronavirus in Ethiopia.

\section{Impacts of COVID-19 on Poorly Equipped Ethiopia's Education System}

In 188 countries, officially the governments have temporarily closed the school and it affected more than 1.5 billion students, $91 \%$ of the total learners globally (this refers to the Official Website of the UNESCO: https://en.unesco.org/covid19/educational response). The education sector is one highly affected by the spread of COVID-19 in Ethiopia. The world including Ethiopia dramatic changed the face of schools and higher education institutions since March 2020. Reich et al. (2020) stated that the situation happened in the first week of March 2020 in the USA and stated as, though the first case has confirmed in the metropolitan city of Seattle in the midweeks of that month, the virus spreads out throughout the country and embarked school closure. They assured as, after days of interruption, most of the schools started online learning to replace the regular classroom. Currently, in the USA, schools running their delivery of education through online and other electronic media (Reich et al., 2020). Months before the USA's above-mentioned educational scenario, COVID-19 drives China's students out of school, and provision has been continuing with the help of updated technologies and internet access to all corners (Zhao et al., 2020). Cognizant to that the online learning harms the students' extracurricular activities including the social skill and communication capabilities that are important for their future career.

Among the sub-Saharan African countries following Nigeria, Ethiopia has the largest number of the population estimated to be more than 110 million by 2020 . The numbers of school enrollments are also one of the largest in the region. However, after the government has learned the devastating impact of COVID-19 from Asian and European countries that resulted in a massive number of students had suspended from the school since March 2020. The closure of schools is now a global phenomenon, but unlike other countries, students in Ethiopia provided neither online nor television and radio teaching for weeks. Since, nearly months from the closure, students in all levels are far apart from their learning and alternative methods of learning never employed. Now, school leaders, principals, teachers, supervisors, supporting staff, and all communities in both public and private institutions become idle. Leaving behind the lagged education 
at all levels has a double devastating effect on the current as well as in the future of the Ethiopian economy.

Of course, in the first two weeks of the closure, higher education teachers have had the order to communicate with their students via email. They were started to send materials, assignments, and projects etc., to facilitate learning but it was demised a soon as the government announced as the students have to leave campus to back home. After university students left the campus, running learning via the internet or electronic media becomes unthinkable because more than $80 \%$ of university students are rural-based without electricity, laptop, smart-phone, desktop, and the world's top expensive internet. Therefore, neither the government nor the universities devised their best possible alternatives to provide learning. Some university students now involve in voluntary activities within their communities to fight the spread of the pandemic. Similarly, instructors have been advised to stay at home and they were limited to get internet access from the university due to this shelter-at-home policy, and subsequently other academic issues have been influenced. This circumstance in Ethiopia might not be an easy way for the students and teachers of higher education institutions to be competent in this highly competitive world.

Top management leaders of the University have been highly engaged in activities that could contain the spread of the Coronavirus. Almost all universities and some high schools are prepared to be uses as isolation spaces for the pandemic virus-infected people. Although universities are lagging from running students' learning, they are contributing critical activities to help poorly established health system to combat the virus. For instance, Bahir Dar University, Debre Markos University, University of Gondar, Wolita Sodo University, Injibara University, Debre Tabor University and Wollo University are some in Ethiopia financially supporting the government and preparing sanitizers, masks, long-lasting foods, shelter and other important inputs used to fight COVID-19 (This refers to the official Facebook page and website of each university).

Similarly, from the nursery school to preparatory school, students' learning has stopped since the day the Prime minister of Ethiopia announced the closure of schools from the global pandemic. Since then, all levels of students were suspended to continue their learning by any means. National examinations have been extended for an unspecified period. Students are in tension due to a lack of clarity from the ministry of education on issues like how the national examination will be prepared and when it will take place. Not only the students but also their parents are worried about the interruptions of normal learning. For elementary school students, after 17 days of interruption, on 3 April 2020, the Ministry of Education has urged the students to follow the educational programs on radio as they declared, "If you have access, you can follow the educational programs via radio". This showed that students' learning is neither mentored by teachers nor supported by their parents. Moreover, Ethiopia has more than $80 \%$ of rural dwellers from the total population. They have no access to electricity, radio, and the internet, etc., and the students' parents also are not yet conscious about how to give time at home for their children to engage with educational activities. Therefore, the 
COVID-19 pandemic highly affects the Ethiopian education system and it drives it towards the brink of educational collapse.

The aforementioned Ethiopian educational scenario may bring it as an exceptional country with a huge number of students without learning. Right now, UNESCO, United Nations, WB, and other international organizations are warning member states to develop and employ alternative technologies to deliver learning for all students. However, the circumstance of Ethiopia becomes different from this urgent message by organizations. It has been building nutshell inequality at national and international levels. As addressed above, some nations' exemplary online provisions of learning withstanding the limitations in students' side effect in respect to extracurricular activities, they all are better than the Ethiopian stagnant provision by far. This difference not only sustains the existing inequality but also assures a high and long-lasting inequality between countries at international level. Within the nation, a disparity between the rural and urban as well as the haves and have-nots becomes highly notable. As seen from above, the ministry of education provides learning for those students from better family and urban areas. Therefore, students from rural, remote, and poor families suspended from learning and perhaps exposed to exploitation in agricultural activities and daily laborer. The event peaks and sustains the existing inequality not only at a student level but also eventually, at family and community levels. Therefore, the Ethiopian government is not on the stance to take measures that mitigate the challenges facing in the closure of schools as a global crisis.

\section{Challenges to Take the Responsive Measures}

Ethiopia has been investing efforts to prepare the teachers, students, and school administers, etc., for technological advancement to apply in the educational arena. The country has developed the National Information and Communication Technology (ICT) Policy and Strategy document in 2017 aiming to establish the overall framework of ICT development in the country, which could facilitate educational provisions (Inception Report, 2018). The main mission of this document was to make every activity including education in Ethiopia on an ICT assisted (Federal Democratic Republic of Ethiopia [FDRE], 2007). ICT applications in the educational endeavors of Ethiopia have only limited the installation of computers (often without internet) in secondary schools and higher education institutions and centrally disseminated TV plasma for secondary and preparatory levels. Addressing the common learning lessons for specific groups of students in a single station was one of the milestones of integrating ICT in the Ethiopian education system (Assefa, 2017; Birbirso, no date available; Alemu, 2017).

However, this situation has to wake up the government, innovators, policymakers, educators, and other stakes, to have something to be done to support the provision of learning even in the time of crises. For instance, in 2008, only 360,000 peoples of Ethiopia use internet service (Wikipedia). By the year 2012, it has an internet penetration rate of $<2 \%$, but other African countries like Morocco, Egypt, Nigeria, Kenya, Sudan, and Djibouti have an internet penetration rate of $51.0 \%, 35.6 \%, 28.4 \%, 28.0 \%$, 
$19.0 \%$, and $7.9 \%$, respectively. In Africa, the average internet penetration rate is $15.6 \%$ and Ethiopia uses less than 1\% of Africa's internet (Atnafu, 2015). In 2016, it shares $0.1 \%$ of the world's internet users with a $4 \%$ penetration rate and 4,288,023 of the total population (more than 101 million) uses the internet often through mobile phones (available from: https://www.internetlivestats.com/internet-users/ethiopia/). Still this condition in Ethiopia has not improved significantly, even when compared with other Sub-Saharan countries.

Let alone the availability of internet and computer for students and teachers like other countries, the accessibility of television and radio is under a question mark in Ethiopia. Since the country is in complete lockdown, providing learning by assuming as the students are accessible to television and radio is a serious problem because almost more than $80 \%$ of students are in a rural area, they cannot move to urban areas to get access of television and radio, library and even to consult their teachers. Even, those students who have access to media for learning may face challenges including technical problems, frequent electric power interruptions, environments they have may not be suitable to attend live lessons attentively and families may not be able to support their disadvantaged children as the teachers do. This haphazard provision of learning only for a very small portion of the students may arouse emotional and psychological problems in both types of students who are accessible and non-accessible to it. In the remote rural area, one of my family's neighbors' daughter who is in the grade six called me and said, "learning is providing in the urban area through radio, I can't access it, I don't have a radio to follow, in the family, nobody is understanding what is going on in my education, does it mean I am excluded from learning? What will happen between students from radio accessed and not accessed areas after the condition becomes normal?..." These all are heart-breaking questions that show emotional and psychological disruptions of the students. Taking into account these challenges and disparities in the provision, the government is moving its efforts forward in some stages for the primary and secondary school students' learning. However, still, neither government nor Minister of Science and Higher Education has said something about the solutions to provide learning for millions of university students interrupted from their education since 16 March 2020 .

\section{Researcher's Remark}

The current stand of the Ethiopian government to run the students learning in a situation of complete lockdown is somehow encouraging for some levels like the primary and secondary schools. Although the government has been struggling to mitigate the effects of COVID-19 through providing learning, challenges are highly visible. Most of the hindrances have related to digital technology and mismanagement. The rural-based lives of the population, expensive and limited access to the internet, unavailability of computers, smartphones and other important devices in almost all households have challenged the provision of education during this period. Moreover, poorly managed 
infrastructure, limited and in most case absence of access to electric power, lack of knowledge to manage technologies all form obstacles for students' learning.

To understand the impact of the novel Coronavirus on the Ethiopian education, in terms of failure and success the television and radio aired learning for the secondary and the primary schools, the fundamental questions need to be raised and answered will determine its status. Questions include: having one of the World's few confirmed cases of the virus, to what extent school closure for an extended period has supported by scientific findings? Are all secondary school students in rural, urban, and suburban areas have had access to television? Does electric power/engine have addressed and wellfunctioning in all areas of the country? Are students and parents knowledgeable and skilled to manage the television's technical problem? Do all households have more than one television to solve conflicts of interest in the family or to minimize the disruptions? Do students stay in the house without engaging in other activities? Are the parents getting awareness or training to help, encourage, and monitor their children's learning? How students' learning to be assessed in television and radio aired learning? How students take notes and ask questions in television and radio learning? Can parents leave home to work by giving responsibility for children to manage their learning through television and radio? Has there any mechanism that teachers can help students in centrally aired education and how? These are some points needed to be scrutinized to figure out the circumstances of strange provisions of education in Ethiopia.

In media, newspapers, and websites, all viewed the event of COVID-19 pandemic as an obstacle to the country's journey towards prosperity. However, this panic from all corners of the country must be taken as a challenge and glorious opportunity for the application of technology in the education systems of the country. Moreover, the situation has to turn the countries effort from both the government and private sectors toward innovating new technologies for educational provision, and to stable the current challenges and to save future generations through opening the platform for international competition. To do so, the government has to allow the involvement of the international private companies in telecommunication and internet supply to provide educational technology, and application and installations of other important infrastructures in rural and urban areas of the country.

\section{References}

Africa Union. (2020) The Africa Centres for

Disease Control and Prevention (Africa CDC) Partners with the United Nations
Development Programme (UNDP) to Strengthen Africa's Response to COVID19 (online). 
https://au.int/en/pressreleases/20200413/a

frica-cdc-undp-strengthen-africas-

response-covid-19

Alemu, M. (2017).Transforming educational practices of Ethiopia into development and the knowledge society through information and communication technology.

Afr Edu Res J, 5(1):1-17.

Assefa T. (2017). Handbook on Digital Learning for K-12 Schools; E-learning Implementation in Ethiopian High schools: Opportunities and Challenges of the Satellite Broadcast Approach. pp413-pp427.

Atnafu, S. (2015). Local Internet Content: the Case of Ethiopia. Retrieved from: https://www.researchgate.net/publication/ 279526100

Birbirso, T. (N.D). Technology for empowering or subjugating teachers: Analysis of Ethiopia's education reform discourse practice. Unpublished in Haramaya University, Dire Dawa, Ethiopia. Available at: http://www.moshe.gov.et/files/157831215 7768.pdf

Inception Report. (2008). Development of National Policy \& Strategic Plan for ICT Implementation in Ethiopian Higher Education (2018-2023). ARS PROGETTI SPA AND ASTEC GLOBAL. Available at:

http://www.moshe.gov.et/files/157831215 7768.pdf

Kidman, G. and Chan, C. H. (2020). What does "crisis" education look like? Int Res Geogra Environ Edu, 29(2):107-111.

Ministry of Health (2020). Ethiopia confirmed the first case of COVID-19 (online).

Available at: http://www.moh.gov.et/ejcc/en/node/194

Reich, J., Buttimer, C. J., Fang, A., Hillaire, G., Hirsch, K., Larke, L., Littenberg-
Tobias, J., Moussapour, R., Napier, A., Thompson, M. \& Slama, R. (2020). Remote learning guidance from state education agencies during the COVID-19 pandemic: A first look. Available at: osf.io/k6zxy/

Sá, M.J. \& Serpa, S. (2020). The global crisis brought about by SARS-CoV-2 and its impacts on education: An overview of the Portuguese panorama. Sci Insigt Edu Front, 5(2):525-530.

The Federal Democratic Republic of Ethiopia. (2007). The National Information and Communication Technology (ICT) Policy and Strategy. Addis Ababa; Ethiopia.

Available at:

http://www.mcit.gov.et/documents/20181/ 22562/The+National+Information+and++ Communication+Technology++\%28ICT\%29+Policy+ and+Strategy/45d74e1f-6eff-4607-bba9342462a7be13

UNESCO. (2020). COVID-19 Educational Disruption and Response (online). Available at: https://en.unesco.org/covid19/educationre sponse

Wikipedia contributors. (2020, March 17). Internet in Ethiopia. In Wikipedia, The Free Encyclopedia. Retrieved 20:29, April 13, 2020, Available at: https://en.wikipedia.org/w/index.php?title =Internet_in_Ethiopia\&oldid=946033736

World Health Organization (2020). Coronavirus disease (COVID-2019) situation reports (online). Available at: https://www.who.int/emergencies/disease s/novel-coronavirus-2019/situationreports/. 